Grow, N, Wirdateti, and Nekaris, K

Does toxic defence in Nycticebus spp. relate to ectoparasites? The lethal effects of slow loris venom on arthropods.

Grow, N, Wirdateti, and Nekaris, K (2014) Does toxic defence in Nycticebus spp. relate to ectoparasites? The lethal effects of slow loris venom on arthropods. Toxicon, 95. pp. 1-5.

doi: 10.1016/j.toxicon.2014.12.005

This version is available: https://radar.brookes.ac.uk/radar/items/90418a2b-88b9-4d88-acf2-afeea3138971/1/

Available on RADAR: August 2016

Copyright (C) and Moral Rights are retained by the author(s) and/ or other copyright owners. A copy can be downloaded for personal non-commercial research or study, without prior permission or charge. This item cannot be reproduced or quoted extensively from without first obtaining permission in writing from the copyright holder(s). The content must not be changed in any way or sold commercially in any format or medium without the formal permission of the copyright holders.

This document is the accepted version of the article. Some differences between the published version and this version may remain and you are advised to consult the published version if you wish to cite from it. 


\section{Does toxic defence in Nycticebus spp. relate to ectoparasites? The lethal effects of slow loris}

1. Little Fireface Project, Garut, Indonesia ; nanda.grow@gmail.com

3. Nocturnal Primate Research Group, Oxford Brookes University, Oxford OX3 0BP, United Kingdom

9 ABSTRACT

The venom produced by slow lorises seems to be toxic both intra- and inter-specifically.

11 In this study we assessed the adaptive properties of their venom to repel ectoparasites. We tested

12 venom from two Indonesian slow loris species: Nycticebus javanicus and N. coucang.

13 Arthropods directly exposed to brachial gland secretions mixed with saliva from both slow loris

14 species were immediately impaired or exhibited reduced activity (76\%), and often died as a

15 result (61\%). We found no significant difference in the result of 60 -minute trials between $N$.

16 coucang and $N$. javanicus $\left[X^{2}(2, \mathrm{n}=140)=2.110, p=0.3482\right]$. While most maggots $(84 \%)$ were

17 initially impaired from the venom after 10 minutes, maggots died after a one-hour trial $42 \%$ of

18 the time. In contrast, at the end of one hour arachnids died $78 \%$ of the time. For all arthropods,

19 the average time to death from exposure was less than 25 minutes $(M=24.40, S D=22.60)$.

20 Ectoparasites including ticks, members of the arachnid order, are known to transmit pathogens to

21 hosts and may be an intended target of the toxic secretions. Our results suggest that one function

22 of slow loris venom is to repel parasites that affect their fitness, and that their topical anointing

23 behaviour may be an adaptive response to ectoparasites. 


\section{INTRODUCTION}

25 Few mammals are known to produce toxic secretions (Ligabue-Braun et al. 2012). The

26 functions of mammal venom vary but include suppressing prey, anti-predator defence and

27 intraspecific competition (Ligabue-Braun et al. 2012). Slow lorises (Nycticebus spp.) are the

28 only primates known to produce venom and do this by combining saliva with oil from a brachial

29 gland in their mouth (Alterman 1995), and licking their fur or biting the intended victim. Here

30 we explore the adaptive significance of venom amongst Indonesian slow lorises in regard to its

31 effects on invertebrates.

32 Nekaris et al. (2013) suggested that slow loris venom might function to repel or defend

33 against predators, conspecifics, prey or ectoparasites. In terms of the latter hypothesis, chemical

34 toxicity is one feature that renders vertebrates as unsuitable hosts for ectoparasites (Weldon

35 2010). Slow lorises have rarely been observed to harbour ectoparasites (Streicher 2004; Nekaris,

36 et al., 2013), and it has been proposed that this is due to the chemicals produced by their saliva,

37 brachial grand secretions, or a combination of the two. Ectoparasites are important selective

38 forces that negatively affect the fitness of their hosts (Moller et al. 1993; Weldon and Carroll

39 2006), and are common in the tropical Southeast Asian countries that slow lorises inhabit

40 (Anastos 1950).

41 We explored whether the secretions produced by slow lorises are lethal to ectoparasites.

42 We examined the behavioural and physiological responses of arthropods to slow loris venom.

43 We predicted that: a) arthropods will die more rapidly after direct exposure to slow loris

44 secretions and b) arthropods will avoid moving to test areas that have been applied with slow

45 loris secretions. 
Study Site

We tested the repellent effects of venom produced by adult wild Javan slow lorises $(N$.

51 javanicus) in an agroforest study site in Garut District, West Java, Indonesia (S76 $6^{\prime} 6$ \& E

$\left.52107^{\circ} 46^{\prime} 5\right)$ and adult wild-born greater slow lorises ( $N$. coucang), recently confiscated from the

53 illegal wildlife trade in Sumatra, at Cikananga Wildlife Centre, Sukabumi District, West Java

$54 \quad\left(\mathrm{~S}^{\circ} 00^{\prime} 23.9 \& \mathrm{E} 108^{\circ} 33^{\prime} 3.9\right)$.

Between July 2013 and January 2014, we collected brachial gland and saliva samples

56 from Javan slow lorises using Sterilin swab kits $(n=49)$. In March 2014, we collected saliva and

57 brachial gland samples from greater slow lorises using cotton swabs stored in sterile glass vials

58 and Salimetrics oral swabs that we centrifuged $(n=42)$. We froze all samples until usage.

59 Following Alterman (1995), we extracted frozen brachial oil with a $2 \mathrm{ml}$ solvent of $6 \%$

60 formic acid, which solvates hydrophilic compounds, or alternatively with a $2 \mathrm{ml}$ solvent of 1:1

$6150 \%$ methanol and 50\% methylene chloride, which is lipid soluble. We only used the

62 methanol:methylene chloride solvent with maggots, as the solvent alone impaired other

63 arthropods. After incubating at room temperature for 30 minutes, we mixed $100 \mu$ aliquots of

64 saliva with the extracted solutions and incubated for an additional 15 minutes. Alternatively, we

65 mixed saliva on swabs with the venom solution and incubated for 15 minutes. In experiments

66 using only saliva, we applied saliva directly with no solvent.

67 Due to remote field conditions, we collected multiple types of insects for use in the

68 experiments, including spiders (Arachnida), maggots (Diptera larvae), ants (Hymenoptera), fleas

69 (Siphonaptera), and caterpillars (Lepidoptera larvae) controlled for length: $2 \mathrm{~cm}$ for maggots; 1 - 
$70 \quad 1.5 \mathrm{~cm}$ for spiders, and $2 \mathrm{~cm}$ for caterpillars. We attempted to sample tick abundance in the

71 study area (Carroll and Schmitmann 1992, Sonenshine 2004); we found no adult ticks in two

72 weeks of surveys, so we substituted spiders as an analogy.

73 Experiments included three types of secretions: brachial gland secretion, saliva, and

74 glandular secretions mixed with saliva. We topically applied the venom solution to subjects in a

75 petri dish. We established controls with an insect of the same size and species treating it only

76 with the solvent, or water in tests using saliva only. The following amounts were applied to the

77 abdomen of each arthropod, avoiding the head: $100 \mu \mathrm{l}$ for those less than $1 \mathrm{~cm}$ in length; $200 \mu \mathrm{l}$

78 for $1.5 \mathrm{~cm}$ length; $300 \mu \mathrm{l}$ for $2 \mathrm{~cm}$ length.

79 We conducted all tests on forward locomoting individuals. We recorded responses at 0-,

80 10-, 30-, and 60-minute intervals: no effect (subject continues locomoting with no response),

81 reduced activity (locomotor activity slows or is disrupted), impaired (motor impairment; forward

82 locomotor activity stops or individual appears to be struggling), death, and time until death.

83

\section{RESULTS}

85 We tested 140 subjects (Arachnida: $n=57$; Siphonaptera: $n=10$; Diptera: $n=41$;

86 Hymenoptera: $\mathrm{n}=12$; Lepidoptera: $\mathrm{n}=10$ ) in 93 experimental trials with 30 control trials. The

87 average time to death for trials that resulted in death $(\mathrm{n}=50)$ was 24.40 minutes $(\mathrm{SD}=22.60)$.

88 Tests using saliva or brachial oil only on fleas $(n=3)$, maggots $(n=3)$, and spiders $(n=10)$

89 did not have a significantly different outcome than using water as the control (Pearson Chi

90 Square: $X^{2}=1.272, p$-value $=0.529, \alpha=0.050$ ). These tests were stopped to preserve the limited

91 samples, and a combination of brachial oil and saliva was used for the remaining tests $(n=73)$.

92 Due to the limited amount of saliva available, we stopped direct tests of saliva after only five 
93 trials in order to preserve the amount of samples. Similarly, 11 tests using brachial secretions

94 only sometimes resulted in initial impairment and more often had no effect for fleas $(\mathrm{n}=3)$,

95 maggots $(\mathrm{n}=3)$, and spiders $(\mathrm{n}=5)$. We used a combination of brachial oil and saliva for the

96 remaining direct application tests $(\mathrm{n}=73)$.

97 Arthropods directly exposed to slow loris brachial gland secretions mixed with saliva

98 from both species were immediately impaired ( $76 \%$ of time), and often died as a result ( $61 \%$ of

99 time); treated arthropods had a significantly different response than those exposed to the solvent

100 alone (Pearson Chi Square: $X^{2}=23.38, p$-value $<0.0001, \alpha=0.050$ ). The immediate results of the

101 application are not included in the analysis, as there are confounding factors from the

102 physiological responses to having a foreign substance applied. We found no significant

103 difference in time of death between spiders and maggots (Student's $t$ - $t=2.048, \mathrm{p}=0.315, \alpha=0.05$ ).

104 While most maggots (84\%) were initially impaired from the venom after 10 minutes, maggots

105 died after a one-hour trial only $42 \%$ of the time (Table 1). In contrast, at the end of one-hour

106 arachnids died $78 \%$ of the time (Table 1). For spiders, after only ten minutes direct application

107 of a venom treatment, $80.00 \%$ were dead, impaired or exhibiting reduced activity (Table 1 ).

108 After one hour, $65.00 \%$ of spiders were dead, and $38.00 \%$ remained impaired and often died

109 immediately after.

110 We found no overall significant difference in the result of the 60-minute trials between $N$.

111 coucang and $N$. javanicus (Pearson $X^{2}: X=2.110, \mathrm{df}=1$, $\mathrm{p}$-value $=0.35, \alpha=0.05$; Table 1 ). For

112 spiders, time until death between $N$. javanicus and $N$. coucang did differ significantly (Kruskal

113 Wallis: $Z=-1.974$, $p$-value $=0.05, \alpha=0.05$ ), where subjects applied with venom of $N$. javanicus

114 took a mean of 39.18 minutes to die compared to 23.38 minutes for $N$. coucang (Fig. 1). We

115 found no significant difference between the effects of male and female venom in time to death 
116 (Pearson Chi Square: $\mathrm{X}^{2}=7.454, \mathrm{p}$-value $=0.11, \alpha=0.05$ ) or in time to death for male, female, and

117 combination male/female venom (ANOVA: $\mathrm{F}=3.0613, p=0.0563, \alpha=0.05$ ).

Table 1. Percentage of arthropods that exhibit no effect, impairment, or death at the end of 10and 60- minute single experimental trials.

122

123

RESULT OF TRIALS

\begin{tabular}{lllllll}
\hline \multicolumn{1}{c}{ Type } & \multicolumn{2}{c}{ Death } & \multicolumn{2}{c}{ Impaired } & \multicolumn{2}{c}{ No Effect } \\
\hline & $\mathbf{1 0} \mathbf{~ m i n}$ & $\mathbf{6 0} \mathbf{~ m i n}$ & $\mathbf{1 0} \mathbf{~ m i n}$ & $\mathbf{6 0} \mathbf{~ m i n}$ & $\mathbf{1 0} \mathbf{~ m i n}$ & $\mathbf{6 0} \mathbf{~ m i n}$ \\
Ant (n=10) & 0.90 & 0.90 & 0 & 0 & 0.10 & 0.10 \\
$\begin{array}{l}\text { Caterpillar } \\
(\mathbf{n = 1 0 )}\end{array}$ & 0.00 & 0.00 & 0.10 & 0.00 & 0.90 & 0.10 \\
$\begin{array}{l}\text { Maggot } \\
(\mathbf{n = 1 9 )}\end{array}$ & 0.00 & 0.42 & 0.84 & 0.26 & 0.16 & 0.32 \\
$\begin{array}{l}\text { Spider } \\
(\mathbf{n = 4 0})\end{array}$ & 0.18 & 0.78 & 0.63 & 0.08 & 0.20 & 0.15 \\
\hline
\end{tabular}

124

Figure 1. Bar chart indicating the proportion of results of the one-hour trial for all tested arthropods (full lethality, motor impairment, or no effect) according to loris species.

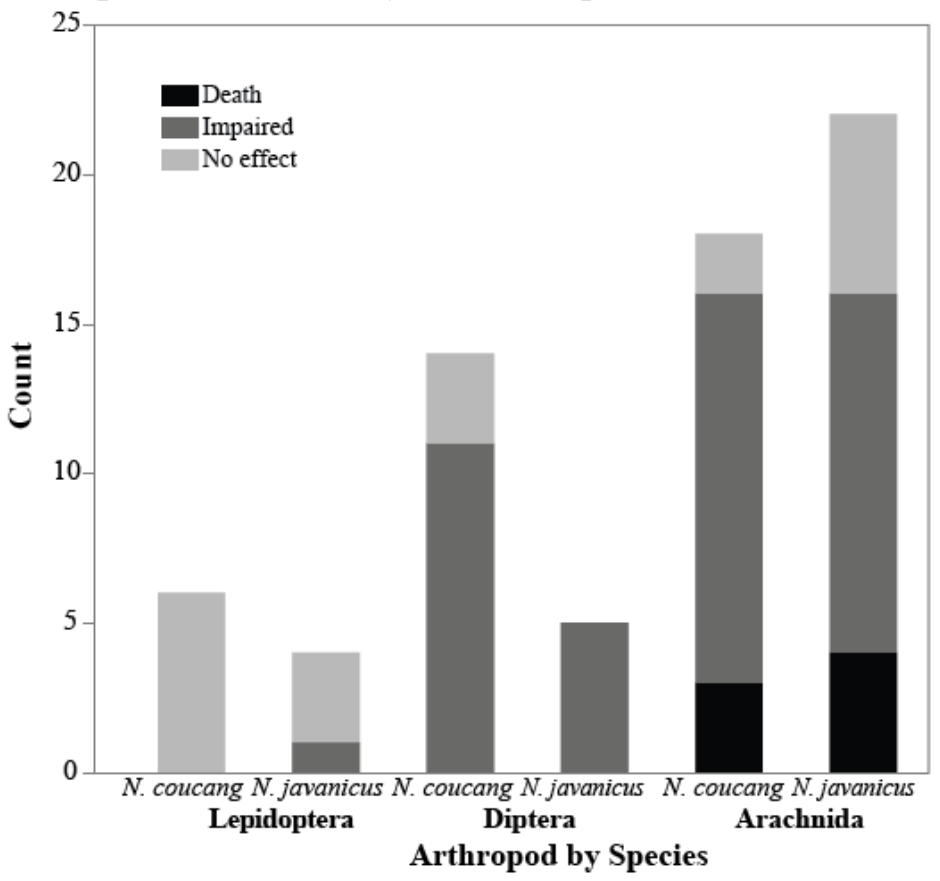




\section{DISCUSSION}

132 We show here that the venom of slow lorises is toxic and often lethal to a variety of

133 insect species. Consistent with previous findings (Alterman 1995), we confirm that this is only

134 the case when brachial grand secretion is combined with saliva. The degree of lethalness of the

135 venom is taxon-specific and varies according to the type of arthropod to which it is exposed. The

136 venom was more lethal for arachnids and ants than for maggots and caterpillars, suggesting its

137 use as a deterrent against some ectoparasites.

138 We suggest in particular that that the anointing behaviour observed in slow lorises may

139 be related to repelling ectoparasites. Slow lorises spend up to $10 \%$ of their active time

140 autogrooming (Rode et al., 2014). Being extremely flexible, slow lorises can lick most parts of

141 the body with the tongue, but also profusely lick their arms and rub them on their head, face and

142 other obtainable body parts (Schulze et al., 1995). The brachial gland secretions of slow lorises,

143 when combined with their saliva and manually or orally applied to their fur, would be a feasible

144 means of reducing ectoparasite load.

145 Other vertebrates are known to use toxic compounds with pesticide qualities. Numerous

146 bird species engage in anting behaviour, taking advantage of the repellent chemical properties

147 that ants leave behind (Weldon \& Carroll 2006). New Guinean pitohuis absorb chemicals from

148 their melyrid beetle prey as a potential predator and parasite defense system (Dumbacher, et al.

149 2004). Other primates, including Cebus, Aotus, and Ateles, anoint themselves with insects and

150 plants in order to ward off ectoparasites, especially ticks (Laska et al. 2007). Careful tri-monthly

151 in-hand examination of all slow loris individuals from this study did not reveal any detectable

152 ectoparasite loads, despite domestic animals in the agroforest environment being heavily infected

153 (Albers et al., 2013). 
154 The fact that slow loris venom has a more pronounced toxic effect on arachnids than

155 other types of arthropods is notable, as ticks are arachnids and a likely recipient of anointed slow

156 loris venom. It is unlikely that topically applied secretions would be repellent to other types of

157 ectoparasites, such as mosquitos, who leave hosts swiftly and do not spend a protracted period of

158 time on hosts as ticks do (Weldon et al. 2011). In ectoparasites, the venom may be sensed by

159 olfactory means and an avoidance response may be triggered. While ectoparasites themselves

160 may not represent a significant impact on the fitness of a host animal in and of themselves,

161 parasites - especially ticks - may carry pathogens that serve as a more potent threat.

162 Ticks are a likely threat for slow lorises, including both Javan and greater slow lorises.

163 Sumatra is home to 22 known species of ticks, while Java is home to 18 different species

164 (Anastos 1950). Although ticks are usually exclusively found at terrestrial and understory levels,

165 ticks have been sampled in the forest canopy, possibly transported from arboreal primate hosts

166 (Loaiza et al. 2013). Specifically, N. coucang is reportedly a known host for Haemaphysalis

167 koningsbergeri (Anastos 1950). The lorises in this study would have been more susceptible to

168 attracting ticks. The wild Javan slow lorises move frequently on the ground due to high levels of

169 disturbance (Rode et al. 2014). The greater slow lorises were kept in captivity in close proximity

170 to many other vertebrate species, but also during their time in trade would have been more

171 susceptible to high stress and low immunity (Streicher 2004). Lack of ectoparasites on both

172 populations provides further support that another factor may contribute to low ectoparasite load -

173 in this case, slow loris venom.

174 Ticks are commonly recognized carriers of pathogens for humans and animals (Dautel

175 1999, Sonenshine 1993). Tick-borne pathogens are common in Southeast Asia, although there is

176 a lack of knowledge on the extent, distribution, and prevalence of these pathogens on both 
177 humans and non-humans (Petney et al. 2007). Despite our lack of understanding of the

178 evolutionary significance of tick-borne pathogens, it is feasible that in areas where ticks are

179 common, defences against this threat may have evolved. In particular, ticks may be more

180 vulnerable to substances applied topically because they are attached to the skin of the host for a

181 prolonged period of time (Carroll et al. 2005). Detailed studies of the biochemistry of

182 Indonesian slow lorises are on-going and may yield further support that slow loris venom

183 contains anti-parasitic properties.

184

\section{Acknowledgements}

186 We thank the authorities Riset and Teknologi (RISTEK), Balai Konservasi Sumber Daya

187 Alam Bandung (BKSDA Bandung), Research Center for Biology, Indonesian Institute of

188 Sciences (LIPI), Konservasi Sumber Daya Alam Garut (KSDA Garut) and Cikananga Wildlife

189 Centre for their support in this project. B.G. Fry, D Rustandi, A Nunur, A Zaelany, Y Nazmi, I

190 Iryantoro, G Fuller, D Spaan, and A Palau Zango, provided valuable insight and assistance. The

191 Leverhulme Trust (RPG-084), the Primate Society of Great Britain, Augsburg Zoo, Columbus

192 Zoo, Cleveland Zoo and the Cleveland Zoo Society funded this project.

193 


\section{REFERENCES}

196 Albers, M., Foitova, I., Abinawanto. \& Nekaris, K.A.I. 2013 Gastrointestinal- and ecto- Parasites in wild Javan slow loris (Nycticebus javanicus).Proceedings of the European Federation of

198 Primatology, Antwerpen 84, 1-2

Alterman, L. 1995 Toxins and toothcombs: potential allospecific chemical defenses in Nycticebus and Perodicticus. In Creatures of the Dark: The Nocturnal Prosimians (eds L. Alterman, G.A. Doyle \& M.K. Izard), pp. 413-424 New York, New York: Plenum Press.

Anastos, G. 1950. The Scutate Ticks, or Ixodidae, of Indonesia. Entomol. Am 30,1-144.

Carroll, J.F., Kramer, M., Weldon, P.J. \& Robbins, R.G. 2005 Anointing chemicals and ectoparasites: effects of benzoquinones from millipedes on the lone star tick, Amblyomma

Carroll \& Scmittmann 1992

Dautel, H., Kahl, O., Siems, K., Oppenrieder, M., Miiller-Kuhrt, L. \& Hilker M. 1999 A novel test system for detection of tick repellents. Entomol. Exp. Appl 91, 431-441.

Dumbacher, J.P., Wako, A., Derrickson, S.R., Samuelson, A., Spande, T.F. \& Daly, J.W. 2004 Melyrid beetles (Choresine): A putative source for the batrachotoxin alkaloids found in poisondart frogs and toxic passerine birds. Proc Natl Acad Sci USA 10, 15857-15860.

218 Laska, M., Verena, B. \& Hernandez Salazar, L.T. 2007 Self-anointing behavior in free-ranging 219 spider monkeys (Ateles geoffroyi) in Mexico. Primates 48, 160-163.

220 Ligabue-Braun, R., Verli, H \& Carlini, C.R. 2012 Venomous Mammals: A review.Toxicon 59, $221680-695$.

222 Loaiza et al 2013

223 Nekaris, K.A.I., Moore, R.S., Rode, J. \& Fry, B.G. 2013 Mad, bad and dangerous to know: the 224 biochemistry, ecology and evolution of slow loris venom. J. Venom. Anim. Toxins. Incl. Trop.

Møller, A.P., Ller, R.D. \& Allander, K. 1993 Parasites and the evolution of host social behavior. Adv. Stud. Behav 22,65.

Petney et al 2007

Rode, E.J., Wirdateti. \& Nekaris, K.A.I. (In press - 2014) Ethology of the Critically Endangered Javan slow loris (Nycticebus javanicus) in West Java. Asian Primates. 
Schulze, H. \& Meier, B. 1995 Behaviour of captive Loris tardigradus nordicus: a qualitative description, including some information about morphological bases of behaviour. In: Creatures of the dark: the nocturnal prosimians. (eds L. Alterman, A. Doyle \& M.K. Izard), pp. 221-249 New York, New York: Plenum Press.

239 Soneshine 1993

Sonenshine, D.E. 2004 Pheromones and other semiochemicals of ticks and their use in tick control. Parasitology 129, 405-425.

Streicher, U. 2004. Aspects of ecology and conservation of the pygmy loris Nycticebus pygmaeus in Vietnam. PhD dissertation, Ludwig Maximilian University, Munich, Germany.

Weldon, P.J. 2004 Defensive anointing: extended chemical phenotype and unorthodox ecology. Chemoecology 14, 1-4.

Weldon, P.J. 2010 Nuisance arthropods, nonhost odors, and vertebrate chemical aposematism. Naturwissenschaften 97, 511-519.

Weldon, P.J. \& Carroll, J.F. 2006 Vertebrate chemical defense: secreted and topically acquired deterrents of arthropods. In: Insect Repellents Principles, Methods, and Users. (eds M. Debboun, S.P. Frances \& D. Strickman) pp. 47-74 CRC Press Taylor \& Francis Group

Weldon, P.J., Carroll, J.F., Kramer, M., Bedoukian, R.H., Coleman, R.E. \& Bernier, U.R. 2011 Anointing chemicals and hematophagous arthropods: responses by ticks and mosquitoes to Citrus (Rutaceae) peel exudates and monoterpene components. J. Chem. Ecol 37, 348-359. 